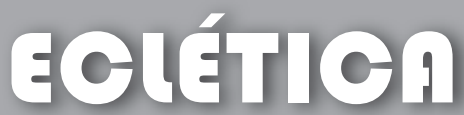 química
}

\section{ESTIMATION OF STANDARD ENTHALPY OF FORMATION OF ALKANES IN GASEOUS STATE BY CALCULATING SIZE, STRUCTURAL AND ELECTRONIC PARAMETERS IN THE MOLECULES.}

Verma,P.S. - Prof.\& Head of Department of Chemistry, University of ajasthan, Jaipur (India); Gorsi, B.L.*; *E-mail-blgorsi.2007@yahoo.com

Kalwania,G.S. and Lovel. Dept of Chemistry, S.K.Govt. P. G. College, Sikar (India)

\begin{abstract}
A quantitative analysis is made on the correlation ship of thermodynamic property, i.e., standard enthalpy of formation $\left(\Delta \mathrm{H}_{\mathrm{f}}{ }^{0}\right)$ with Kier's molecular connectivity index $\left({ }^{1} \mathrm{X}^{\mathrm{v}}\right)$, vander waal's volume ( $\mathrm{Vw}$ ) electrotopological state index (E) and refractotopological state index (R) in gaseous state of alkanes. The regression analysis reveals a significant linear correlation of standard enthalpy of formation $\left(\Delta \mathrm{H}_{\mathrm{f}}{ }^{0}\right)$ with ${ }^{1} \mathrm{X}^{\mathrm{v}}, \mathrm{Vw}, \mathrm{E}$ and $\mathrm{R}$. The equations obtained by regression analysis may be used to estimate standard enthalpy of formation $\left(\Delta \mathrm{H}_{\mathrm{f}}{ }^{0}\right)$ of alkanes in gaseous state.
\end{abstract}

Keywords: Kier's molecular connectivity (1Xv); vander waal's volume (Vw); Electrotopological state index (E); Refractotopological state (R).

\section{INTRODUCTION}

Standard enthalpy of formation is a basic thermodynamic property. It is used in chemical engineering calculations. Experimental measure-

ments of standard enthalpy of formation $\left(\Delta \mathrm{H}_{\mathrm{f}}{ }^{0}\right)$ involve experimental difficulties and they are not always feasible and the corresponding methods possess real drawbacks. Consequently, it is necessary to resort to a theoretical calculation of these parameters. This option is now accessible because an important, fruitful and current field of research.

The additive approach applied to the estimation of thermo physical properties was systematically developed by S.W.Benson and coworkers $^{1-3}$. Many topological distances based indices as molecular descriptors for $\mathrm{QSAR}^{4,5}$ and additive scheme ${ }^{6}$ have been developed for the es- timation of enthalpy of formation of organic compounds.

One of the most important points in such research is the selection of adequate descriptors containing the information stored in the molecular structure. The quite satisfactory results of applying regression analysis may be used to calculate heats of formation seems to indicate this way is a suitable one to compute the enthalpy content of molecules. Since results are good enough and errors are nearly the same as experimental uncertainties, the equations show to be a suitable method to systematize data and to derive certain rules regarding the structural elements and group contribution to the molecular enthalpy of formation.

There are a wide variety of molecular descriptors to be used as independent variable and this large number of possibilities allows one to make quite different choices to perform the calculation 
and to interpret in a meaningful way the results. In view of the above, it is thought that heat enthalpies of formation which depend upon the size, strcture, electronic environment and complexity ted with size, structure and con i.e. first order valence connectivity $\left({ }^{1} \mathrm{X}^{v}\right.$, , vander waal's volume $(\mathrm{Vw})$, electrotopological state in$\operatorname{dex}(\mathrm{E})$ and refractotopological state (R) in alkanes. Previously we have established a significant quantitative co-relationship of these parameters with diamagnetic susceptibility of many organic compounds ${ }^{7,8}$. The aim of this paper is to obtain the correlation equations of $\left(\Delta \mathrm{H}_{\mathrm{f}}{ }^{0}\right)$ with ${ }^{1} \mathrm{X}^{\mathrm{v}}, \mathrm{Vw}$, $\mathrm{E}$ and $\mathrm{R}$ parameters.
$\mathrm{X}^{\mathrm{v}}=\sum\left(\delta \mathrm{i}^{\mathrm{v}} \cdot 3 \delta \mathrm{j}^{\mathrm{v}}\right)^{-1 / 2}$

(1) or edges in such a graph, $\delta \mathrm{i}^{\mathrm{v}}$ and $\delta \mathrm{j}^{\mathrm{v}}$ are numbers assigned to each atom reflecting the numbers of toms adjacent or connected to which are formally bonded the acm (i) and (j) term $\left(\delta \mathrm{i}^{\mathrm{v}}\right)^{\text {is }}$ defined as

$$
\delta \mathrm{i}^{\mathrm{v}}=\frac{-}{\mathrm{Z}-\mathrm{Zi}^{\mathrm{v}}-1}
$$

Where $\mathrm{Zi}^{\mathrm{v}}=$ number of valence electron of atom (i), $\mathrm{Z}=$ atomic number of atom (i) and hi $=$ number of hydrogen atoms attached to atom

Table (1) shows the atom connectivity $\left(\delta i^{\mathrm{v})}\right.$ values in different groups as calculated by eq.(2) term $\left(\delta \mathrm{i}^{\vee}\right.$ is defined as

1. Calculation of Kier` $s^{9}$ molecular connectivity $\left({ }^{\prime}{ }^{v}\right)$

It is calculated by a hydrogen suppressed graph of the molecule ${ }^{10}$. The first order valence connectivity $\left({ }^{1} \mathrm{X}^{v}\right)$ is given by eq. 1 :

Table 1. Atom connectivity $\left(\delta \mathrm{i}^{\mathrm{v}}\right)$ values in different groups

\begin{tabular}{cccc}
\hline Groups & $\delta \mathrm{i}^{\mathrm{v}}$ & Groups & $\delta \mathrm{i}^{\mathrm{v}}$ \\
\hline$-\mathrm{CH}_{3}$ & 01 & $=\mathrm{CH}_{2}$ & 02 \\
$\equiv \mathrm{CH}$ & 03 & $-\mathrm{OH}$ & 05 \\
$-\mathrm{NH}_{2}$ & 03 & $\mathrm{O}$ & 06 \\
$-\mathrm{NH}-$ & 04 & $\mathrm{C}=\mathrm{O}$ & 06 \\
$-\mathrm{C} \equiv \mathrm{N}$ & 05 & Furan O & 06 \\
$-\mathrm{C}=\mathrm{NH}$ & 04 & $\mathrm{O}=\mathrm{N} \mathrm{O}$ & 06 \\
$\mathrm{~N}$ or Pyridine $\mathrm{N}$ & 05 & $\mathrm{H}_{2} \mathrm{O}$ & 04 \\
$\mathrm{NH}_{3}$ & 02 & $\mathrm{~F}$ & $(-) 20$ \\
$\mathrm{NH}_{4}$ & 01 & $\mathrm{Cl}$ & 0.690 \\
$>\mathrm{N}^{+}$ & 06 & $\mathrm{Br}$ & 0.254 \\
$=\mathrm{N} \mathrm{H}_{2}^{+}$ & 03 & $\mathrm{I}$ & 0.085 \\
\hline
\end{tabular}

2. Calculation of vander waal's Volume $(\mathrm{Vw})$ :

Another atomic parameter accounting for the size of a molecule, the vander waal's volume $(\mathrm{Vw})$ may be calculated as suggested by Bond ${ }^{11}$ The atoms are assumed to be spherical and necessary corrections for the overlap in the hydroge chain are also incorporated ${ }^{12}$

$V w=\sum n_{i} a_{i}+\left[\sum\right.$ corrections for bonds + corrections for no. of branching$$
\text { (3) }
$$

Table 2. vander waal's volume of different atoms

\begin{tabular}{cccccc}
\hline Atom & $\begin{array}{c}\text { Sphere volume } \\
10^{2} \mathrm{~A}^{03}\end{array}$ & Atom & $\begin{array}{c}\text { Sphere volume } \\
10^{2} \quad \mathrm{~A}^{03}\end{array}$ & Atom & $\begin{array}{c}\text { Sphere volume } \\
10^{2} \mathrm{~A}^{03}\end{array}$ \\
\hline $\mathrm{C}$ & 0.206 & $\mathrm{H}$ & 0.056 & $\mathrm{~N}$ & 0.141 \\
$\mathrm{O}$ & 0.115 & $\mathrm{~S}$ & 0.244 & $\mathrm{~F}$ & 0.115 \\
Aliphatic $\mathrm{Cl}$ & 0.206 & Aromatic Cl & 0.244 & Aliphatic Br & 0.244 \\
Aromatic $\mathrm{Br}$ & 0.287 & Aliphatic I & 0.335 & Aromatic I & 0.388 \\
\hline
\end{tabular}

Table 3. Correction values of vander waal's volume for sphere overlapping due to covalent bonding and for Branching

\begin{tabular}{cccccc}
\hline Bond & $\begin{array}{c}\text { Correction value } \\
10^{2} \mathrm{~A}^{03}\end{array}$ & Bond & $\begin{array}{c}\text { Correction value } \\
10^{2} \mathrm{~A}^{03}\end{array}$ & Bond & $\begin{array}{c}\text { Correction value } \\
10^{2} \mathrm{~A}^{03}\end{array}$ \\
\hline C-C & -0.078 & C-H & -0.043 & C-N & -0.065 \\
C-O & -0.056 & C-S & -0.066 & C-F & -0.056 \\
Aliph. C-Cl & --0.058 & Arom C-Cl & -0.066 & Aliph. C-Br & -0.060 \\
Arom. C-Br & -0.068 & Aliph.C-I & -0.063 & Arom. C-I & -0.072 \\
C-B & -0.113 & H-H & -0.030 & N-H & -0.038 \\
N-N & -0.050 & N-O & -0.042 & N-S & -0.061 \\
O-H & -0.034 & O-B & -0.079 & S-H & -0.040 \\
S-S & -0.062 & S-F & -0.052 & C=C & -0.094 \\
C=N & -0.072 & C=O & -0.068 & C=S & -0.081 \\
N=N & -0.061 & N=O & -0.053 & $\mathrm{~S}=\mathrm{O}$ & -0.057 \\
C $=\mathrm{C}$ & -0.0101 & $\mathrm{C}=\mathrm{N}$ & -0.079 & Arom.C=C & -0.086 \\
Branching for & & & & & \\
Saturated bond & -0.050 & & & & \\
Except bonding & & & & & \\
with H & & & & & \\
\hline
\end{tabular}

$\mathrm{V} w$ = vander waal's volume of the molecules

ni $=$ no. of atoms.

Table 2 shows vander waal's volume of different atoms and table 3 shows correction values of vander waal's volume for sphere overlapping value of vander waal's may be calculated as eq. 3 . due to covalent bonding and for Branching. The 
3. Calculation of electrotopological state Index (E-State):

This index is developed from chemical graph theory and uses the chemical graph (hydrogen -suppressed skeleton) for generation of atom -level structure indices. This index recognizes that every atom in a molecule is unique, and this uniqueness arises from differences in the electronic and topological environment of each atom. This descriptor is formulated as an intrinsic value $\mathrm{Ii}$ plus a perturbation given by the electronic influence of the topological bnvironment of the mo-

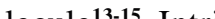
calculated as follow: calculated as follow:$$
\mathrm{I}_{\mathrm{i}}=\left[(2 / \mathrm{N})^{2} \delta \mathrm{v}+1\right] / \delta
$$

Where $\mathrm{N}$ is the principal quantum number of the atom $\mathrm{i}, \delta \mathrm{v}$ the number of valence electrons in the skeleton $\left(\mathrm{Z}_{\mathrm{v}}\right.$-hi) $; \delta$ the number of $\sigma$ electrons in the skeleton $(\sigma-\mathrm{h})$. For a skeleton, $\mathrm{Z}_{\mathrm{v}}$ the total number of electrons on the atom . $\sigma$ the number of electrons in the $\sigma$ orbitals, $h$ the number of $\sum$ ni Ii

bonded hydrogen atom. E-state for an atom i in molecule (Si) is given by

$\mathrm{Si}=\mathrm{Ii}+\sum \Delta \mathrm{Ii}$

$\Delta \mathrm{Ii}=$ quantifies the perturbation (5) on the intrinsic atom value. This perturbation is 作 assuned to be a function $\Delta \mathrm{Ii}=\sum(\mathrm{Ii}-\mathrm{Ij}) / \mathrm{r}^{2}$

Where, $r_{i j}$ is the number of atoms in the shortest path between atoms $i$ and $j$ including both $i$ and $j$.

The difference in intrinsic values $\Delta \mathrm{Ii}$ for a pair of skeletal atoms encode both electronic and topological attributes that arise from electro negativity differences and skeletal connectivity.

Table 4. Intrinsic state valence Ii of atoms in some groups

\begin{tabular}{cccccc}
\hline Group & Ii & Group & Ii & Group & Ii \\
\hline$>\mathrm{C}<$ & 1.250 & $>\mathrm{CH}-$ & 1.333 & $-\mathrm{CH}_{2}-$ & 1.5 \\
$>\mathrm{C}=$ & 1.667 & $-\mathrm{S}-$ & 1.833 & $-\mathrm{CH}_{3,}=\mathrm{CH}-,>\mathrm{N}-$ & 2.00 \\
$-\mathrm{I}$ & 2.12 & $\equiv \mathrm{C}-,-\mathrm{NH}-$ & 2.5 & $-\mathrm{Br}$ & 2.75 \\
$=\mathrm{CH}_{2},=\mathrm{N}-$ & 3.00 & $-\mathrm{SH}$ & 3.222 & $-\mathrm{O}-$ & 3.500 \\
$=\mathrm{CH},-\mathrm{NH}_{2}$ & 4.00 & $-\mathrm{Cl}$ & 4.111 & $\equiv \mathrm{N},-\mathrm{OH}$ & 6.00 \\
$=\mathrm{O}$ & 7.00 & $-\mathrm{F}$ & 8.000 & & \\
\hline
\end{tabular}

\section{Calculation of refractotopological state Index} (R-state):

The $\mathrm{R}$ state index is also developed from the chemical graph theory. This index is based on the influence of dispersive forces of each atom on the other atom in the molecule, modified by molecular topology. Crippen et al ${ }^{16}$ reported the atomic cular topology. Crippen et al ${ }^{16}$ reported the atomic
refractivity values of the topological environment refractivity values of the topological environment of each skeleton atom in the molecule. The evaluation of the individual atomic refractivity value
(Calculated by Ghose and Crippen ${ }^{16}$ ) is based on the idea that the sum of the atomic values ( $\alpha \mathrm{i})$

Where, $\mathrm{ni}=$ No. of atoms $; \alpha \mathrm{i}=$ Atomic

Table 5. Atomic refractivity values as calculated by Ghose and Crippen used in the analysis

\begin{tabular}{cccccc}
\hline Atom Type & $\begin{array}{c}\text { Atomic } \\
\text { Refractivity }\end{array}$ & Atom Type & $\begin{array}{c}\text { Atomic } \\
\text { Refractivity }\end{array}$ & Atom Type & $\begin{array}{c}\text { Atomic } \\
\text { Refractivity }\end{array}$ \\
\hline $\mathrm{C}\left(\mathrm{sp}^{3}\right)$ & 2.816 & $\mathrm{C}\left(\mathrm{sp}^{2}\right)$ & 3.828 & $\mathrm{C}(\mathrm{sp})$ & 3.897 \\
$\mathrm{C}(\mathrm{Ar})$ & 3.509 & $\mathrm{C}=\mathrm{X}$ & 3.089 & $\mathrm{H}$ & 0.916 \\
$-\mathrm{O}-$ & 1.635 & $=\mathrm{O}$ & 1.796 & $\mathrm{O}=\mathrm{N}$ & 2.141 \\
$\mathrm{~N}\left(\mathrm{sp}^{3}\right)$ & 3.010 & $\mathrm{~N}\left(\mathrm{sp}^{2}\right), \mathrm{N}(\mathrm{sp})$ & 3.201 & $\mathrm{~N}(\mathrm{Ar})$ & 2.766 \\
$\mathrm{NO}_{2}$ & 3.505 & $\mathrm{Ar}-\mathrm{N}=\mathrm{X}$ & 3.810 & $\mathrm{~F}$ & 1.063 \\
$\mathrm{Cl}$ & 5.611 & $\mathrm{Br}$ & 8.678 & $\mathrm{I}$ & 13.874 \\
$\mathrm{~S}\left(\mathrm{sp}^{3}\right)$ & 7.319 & $\mathrm{~S}\left(\mathrm{sp}^{2}\right)$ & 9.168 & R-SO-R & 6.076 \\
\hline
\end{tabular}
Therefore, the total of sum of the differences in intrinsic values,

$\Sigma \Delta \mathrm{Ii}$, due to perturbation for a whole molecule is zero i.e.. $\sum \Delta \mathrm{Ii}=0$ so,

$\mathrm{Si}=\mathrm{Ii}$

Therefore, E- state for a molecule $=\sum$ ni Si or

\section{RESULTS AND DISCUSSION:}

The values of standard heat enthalpy of formation $\left(\Delta \mathrm{H}_{\mathrm{f}}^{0}\right.$ of gases are taken from literature. ${ }^{17-21}$ Standard heat enthalpies $\left(\Delta \mathrm{H}_{\mathrm{f}}^{0}\right.$ are taken in kilo calories per mole at atmospheric pressure at $298.15 \mathrm{~K}$ in gas phase. The values of ${ }^{1} \chi^{\mathrm{v}}, \mathrm{V}$ E $\left(\Delta \mathrm{H}_{\mathrm{f}}^{0}\right.$ )

The regression analysis reveals that the correlations of standard heat enthalpies $\left(\Delta \mathrm{H}^{0}\right)$ with the molecular connectivity $\left({ }^{1} \chi^{v}\right) \&$ van der waal volume $\left(\mathrm{V}_{\mathrm{w}}\right)$ show very low level of significance , but with the inclusion of indicator variable (I), i.e, $\mathrm{I}=0$ for straight chain and I = 1 for branched alkanes, shows high level of significance and are shown by equations (10) \& (11).

$\Delta \mathrm{H}^{0}=-9.829( \pm 0.175)^{1} \chi^{\mathrm{v}}-4.871( \pm 0.670)$ $-11.288$

being related to the molecular value of the molar refractivity:

$\mathrm{R}$ (molecule) ${ }_{\text {calc. }}=\sum$ ni $\alpha \mathrm{i}$.

refractivity value

$\Delta \mathrm{H}_{\mathrm{f}}{ }^{0}=-31.724( \pm 0.477) \mathrm{V}_{\mathrm{w}}-4.979( \pm 0.574)$ $-7.628$

$\mathrm{N}=45, \mathrm{r}=0.996, \mathrm{~s}=1.711, \mathrm{~F}(2,42)=2362.53$ Both equations show almost $100 \%$ cor-
The correlations of standard heat enthalpies $\left(\Delta \mathrm{H}^{0}\right.$ with electrotopological state index (E) and refractotopological state index $(\mathrm{R})$ have been given by equations (12) \& (13).

$\Delta \mathrm{H}_{\mathrm{f}}{ }^{0}=-3.259( \pm 0.023) \mathrm{E}-7.573$

$\mathrm{N}=45, \mathrm{r}=0.999, \mathrm{~s}=0.810, \mathrm{~F}(1,43)=19512.99$

$\Delta \mathrm{H}_{\mathrm{f}}{ }^{0}=-1.033( \pm 0.013) \mathrm{R}-11.114$

$\mathrm{N}=46, \mathrm{r}=0.997, \mathrm{~s}=1.452, \mathrm{~F}(1,44)=6581.835$

These equations show the high level of significance. Because, correlation coefficients and $\mathrm{F}$ value is again at $99 \%$ level [ $\mathrm{F}_{44}^{1}(0.01)=7.31$ ] ,99.8\% \& $99.4 \%$

variance $\left(r^{2}=0.998 \& 0.994\right)$ high.Standard deviations have minimum variation about the line of regression. All these factors show perfect correlations.

Experimental and theoretical values of standard heat enthalpies of formation $\left(\Delta \mathrm{H}_{\mathrm{f}}^{0}\right.$ o some alkanes calculated by equations (10),(11) (12) and (13) shows good agreement and are listed in tables 6. \& 7. relation. It shows that branching in chains plays an important role in the correlations of the molecular connectivity $\left({ }^{1} \chi^{v}\right)$ \& van der waals volume $(\mathrm{V})$ with the standard heat enthalpies $\left(\Delta \mathrm{H}_{0}\right.$ of he alkanes. In the equation (10) \& (11), the $\mathrm{F}$ values are significant at $99 \%$ level $\left[F^{2}(0.01)=5.1\right.$ ues are signiffcat a $9 \%$ leve $\left[\mathrm{F}^{2}(0.01)=5.18\right.$ and $\left(r^{2}=0.988 \& 0.992\right)$ respectively. 
Table 6. Experimental and theoretical calculated values of $\Delta \mathrm{HfO}$ by $1 \mathrm{Xv} \& \mathrm{Vw}$ parameters in alkanes

\begin{tabular}{|c|c|c|c|c|c|c|}
\hline Name of compound & $1 \mathrm{Xv}$ & $\mathrm{Vw}$ & I & & $\Delta \mathrm{HfO}$ & \\
\hline & & & & Exp.value & Cald.Eq.10 & Cald.Eq.11 \\
\hline Methane & 0.000 & 0.258 & 0 & -17.890 & * & -15.813 \\
\hline Ethane & 1.000 & 0.412 & 0 & -20.240 & -21.117 & -20.699 \\
\hline Propane & 1.414 & 0.566 & 0 & -24.820 & -25.186 & -25.584 \\
\hline n-Butane & 1.914 & 0.720 & 0 & -30.150 & -30.100 & -30.470 \\
\hline 2-Methyl propane & 1.731 & 0.670 & 1 & -32.150 & -33.173 & -33.862 \\
\hline n-Pantane & 2.414 & 0.874 & 0 & -35.000 & -35.015 & -35.355 \\
\hline 2-Methyl butane & 2.269 & 0.824 & 1 & -36.920 & -38.461 & -38.748 \\
\hline 2,2-Dimethyl propane & 2.000 & 0.774 & 1 & -39.170 & -35.817 & -37.162 \\
\hline n-Hexane & 2.914 & 1.028 & 0 & -39.960 & -39.930 & -40.241 \\
\hline 2-Methyl pentane & 2.769 & 0.978 & 1 & -41.660 & -43.375 & -43.633 \\
\hline 3-Methyl pentane & 2.807 & 0.978 & 1 & -41.020 & -43.749 & -43.633 \\
\hline 2,2-Dimethyl butane & 2.560 & 0.928 & 1 & -44.350 & -41.321 & -42.047 \\
\hline 2,3-Dimethyl butane & 2.641 & 0.928 & 1 & -42.490 & -42.107 & -42.047 \\
\hline Heptane & 3.414 & 1.182 & 0 & -44.880 & -44.844 & -45.126 \\
\hline 2-Meyhyl hexane & 3.269 & 1.132 & 1 & -46.590 & -48.290 & -48.519 \\
\hline 3-Mehtyl hexane & 3.307 & 1.132 & 1 & -45.960 & -48.663 & -48.519 \\
\hline 2,2-Dimethyl pentane & 3.061 & 1.082 & 1 & -49.270 & -46.235 & -46.933 \\
\hline 2,3-Dimethy pentane & 3.179 & 1.082 & 1 & -47.620 & -47.405 & -46.933 \\
\hline 2,4-Dimethyl pentane & 3.124 & 1.082 & 1 & -48.280 & -46.865 & -46.933 \\
\hline 2,2,3-Trimethyl butane & 2.942 & 1.032 & 1 & -48.950 & -45.076 & -45.346 \\
\hline Octane & 3.914 & 1.336 & 0 & -49.820 & -49.759 & -50.011 \\
\hline 2-Methyl heptane & 3.769 & 1.286 & 1 & -51.500 & -53.204 & -53.404 \\
\hline 3-Methyl heptane & 3.807 & 1.286 & 1 & -50.820 & -53.578 & -53.404 \\
\hline 4-Methyl heptane & 3.807 & 1.286 & 1 & -50.690 & -53.578 & -53.404 \\
\hline 2,2-Dimethyl hexane & 3.560 & 1.236 & 1 & -53.710 & -51.150 & -51.818 \\
\hline 2,3-Dimethyl hexane & 3.679 & 1.236 & 1 & -51.130 & -52.320 & -51.818 \\
\hline 2,4-Dimethylhexane & 3.662 & 1.236 & 1 & -52.440 & -52.153 & -51.818 \\
\hline 2,5-Dimethylhexane & 3.624 & 1.236 & 1 & -53.210 & -51.779 & -51.818 \\
\hline 3,3-Dimethylhexane & 3.620 & 1.236 & 1 & -52.610 & -51.740 & -51.818 \\
\hline 3,4-Dimethylhexane & 3.717 & 1.236 & 1 & -50.910 & -52.693 & -51.818 \\
\hline Nonane & 4.414 & 1.490 & 0 & -54.740 & -54.673 & -54.897 \\
\hline 2,2,3-Trimethylpentane & 3.480 & 1.186 & 1 & -52.610 & -50.364 & -50.232 \\
\hline 2,2,4-Trimethylpentane & 3.415 & 1.186 & 1 & -53.570 & -49.725 & -50.232 \\
\hline 2,3,3-Trimethylpentane & 3.502 & 1.186 & 1 & -51.730 & -50.580 & -50.232 \\
\hline 2,3,4-Trimethylpentane & 3.551 & 1.186 & 1 & -51.970 & -51.062 & -50.232 \\
\hline 3-Ethyl pentane & 3.345 & 1.132 & 1 & -45.330 & -49.037 & -48.519 \\
\hline
\end{tabular}

\begin{tabular}{lcccccc} 
3-Methyl-3-ethyl pentane & 3.680 & 1.236 & 1 & -51.380 & -52.329 & -51.818 \\
2-Methyl-3-ethyl pentane & 3.717 & 1.236 & 1 & -50.480 & -52.693 & -51.818 \\
Undecane & 5.414 & 1.798 & 0 & -64.600 & -64.502 & -64.668 \\
Hexadecane & 7.914 & 2.568 & 0 & -89.230 & -89.075 & -89.095 \\
Nonadecane & 9.414 & 3.030 & 0 & -104.000 & -103.818 & -103.752 \\
Octadecane & 8.914 & 2.876 & 0 & -99.080 & -98.904 & -98.866 \\
Pentadecane & 7.414 & 2.414 & 0 & -84.310 & -84.16 & -84.210 \\
Tetradecane & 6.914 & 2.260 & 0 & -79.380 & -79.246 & -79.324 \\
Tridecane & 6.414 & 2.106 & 0 & -74.450 & -74.331 & -74.439 \\
I=0 for Straight Chain & $\mathrm{I}=1$ for Branched Chain & & & & \\
\hline
\end{tabular}

Table 7. Experimental and theoretical calculated values of $\Delta \mathrm{HfO}$ by $\mathrm{E}$ and $\mathrm{R}$ parameters in alkanes

\begin{tabular}{|c|c|c|c|c|c|}
\hline Name of compound & $\mathrm{E}$ & $\mathrm{R}$ & & $\Delta \mathrm{Hf0}$ & \\
\hline & & & Exp.value & Cald.Eq.12 & Cald.Eq.13 \\
\hline Methane & * & 6.478 & -17.890 & * & -17.806 \\
\hline Ethane & 4.000 & 11.125 & -20.240 & -20.611 & -22.606 \\
\hline Propane & 5.500 & 15.771 & -24.820 & -25.500 & -27.405 \\
\hline n-Butane & 7.000 & 20.418 & -30.150 & -30.389 & -32.205 \\
\hline 2-Methyl propane & 7.333 & 20.418 & -32.150 & -31.475 & -32.205 \\
\hline n-Pantane & 8.500 & 25.065 & -35.000 & -35.279 & -37.006 \\
\hline 2-Methyl butane & 8.833 & 25.065 & -36.920 & -36.364 & -37.006 \\
\hline 2,2-Dimethyl propane & 9.250 & 25.065 & -39.170 & -37.723 & -37.006 \\
\hline n-Hexane & 10.000 & 29.712 & -39.960 & 40.168 & -41.806 \\
\hline 2-Methyl pentane & 10.333 & 29.712 & -41.660 & -41.253 & -41.806 \\
\hline 3-Methyl pentane & 10.333 & 29.712 & -41.020 & -41.253 & -41.806 \\
\hline 2,2-Dimethyl butane & 10.750 & 29.712 & -44.350 & -42.612 & -41.806 \\
\hline 2,3-Dimethyl butane & 10.666 & 29.712 & -42.490 & -42.338 & -41.806 \\
\hline Heptane & 11.500 & 34.359 & -44.880 & -45.057 & -46.606 \\
\hline 2-Meyhyl hexane & 11.833 & 34.359 & -46.590 & -46.142 & -46.606 \\
\hline 3-Mehtyl hexane & 11.833 & 34.359 & -45.960 & -46.142 & -46.606 \\
\hline 2,2-Dimethyl pentane & 12.250 & 34.359 & -49.270 & -47.501 & -46.606 \\
\hline 2,3-Dimethy pentane & 12.166 & 34.359 & -47.620 & -47.228 & -46.606 \\
\hline 2,4-Dimethyl pentane & 12.166 & 34.359 & -48.280 & -47.228 & -46.606 \\
\hline 2,2,3-Trimethyl butane & 12.583 & 34.359 & -48.950 & -48.587 & -46.606 \\
\hline Octane & 13.000 & 39.005 & -49.820 & -49.946 & -51.405 \\
\hline 2-Methyl heptane & 13.333 & 39.005 & -51.500 & -51.031 & -51.405 \\
\hline 3-Methyl heptane & 13.333 & 39.005 & -50.820 & -51.031 & -51.405 \\
\hline 4-Methyl heptane & 13.333 & 39.005 & -50.690 & -51.031 & -51.405 \\
\hline 2,2-Dimethyl hexane & 13.750 & 39.005 & -53.710 & -52.391 & -51.405 \\
\hline 2,3-Dimethyl hexane & 13.666 & 39.005 & -51.130 & -52.117 & -51.405 \\
\hline
\end{tabular}




\begin{tabular}{lccccc} 
2,4-Dimethylhexane & 13.666 & 39.005 & -52.440 & -52.117 & -51.405 \\
2,5-Dimethylhexane & 13.666 & 39.005 & -53.210 & -52.117 & -51.405 \\
3,3-Dimethylhexane & 13.750 & 39.005 & -52.610 & -52.391 & -51.405 \\
3,4-Dimethylhexane & 13.666 & 39.005 & -50.910 & -52.117 & -51.405 \\
Nonane & 14.500 & 43.652 & -54.740 & -54.835 & -56.206 \\
2,2,3-Trimethylpentane & 14.083 & 39.005 & -52.610 & -53.476 & -51.405 \\
2,2,4-Trimethylpentane & 14.083 & 39.005 & -53.570 & -53.476 & -51.405 \\
2,3,3-Trimethylpentane & 14.083 & 39.005 & -51.730 & -53.476 & -51.405 \\
2,3,4-Trimethylpentane & 13.999 & 39.005 & -51.970 & -53.202 & -51.405 \\
3-Ethyl pentane & 11.833 & 34.359 & -45.330 & -46.142 & -46.606 \\
3-Methyl-3-ethyl pentane & 13.750 & 39.005 & -51.380 & -52.391 & -51.405 \\
& & & & & $-00 n+1-$ \\
2-Methyl-3-ethyl pentane & 13.666 & 39.005 & -50.480 & -52.117 & -51.405 \\
2,2,3,3-Tetramethylbutane & 14.500 & 39.005 & -53.990 & -54.835 & -51.405 \\
Undecane & 17.500 & 52.946 & -64.600 & -64.613 & -65.806 \\
Hexadecane & 25.000 & 76.180 & -89.230 & -89.059 & -89.806 \\
Nonadecane & 29.500 & 90.120 & -104.000 & -103.727 & -104.206 \\
Octadecane & 28.000 & 85.473 & -99.080 & -98.838 & -99.406 \\
Pentadecane & 23.500 & 71.533 & -84.310 & -84.170 & -85.006 \\
Tetradecane & 22.000 & 66.886 & -79.380 & -79.281 & -80.206 \\
Tridecane & 20.500 & 62.239 & -74.450 & -74.392 & -75.406 \\
\hline
\end{tabular}

[18] and Related Compounds",Carnegie Press Pittsburgh, Pa., 1953.

[19] J.G. Aston, "Some Observations on the Thermodynamics of Hydrocarbons and Related Compounds", Chem.. Rev., 27 (1940)59-73.

[20] K.S. Pitzer, "Chemical Equilibria, Free Energies and Heat Contents for gaseous Hydrocarbons”, Chem. Rev., 27 (1940)75-83.

[21] M. Sounders, Jr., C.S. Matthewa and C.O. Hurd "Entropy and Heat of

[22] Formation of Hydrocarbon Vapors”, Ind. Eng. Chem. , 41 (1949)1048-1056.

[23] F.D. Rossini, "Heats of Formation of Gaseous Hydrocarbons", Chem. Rev., 27 (1940)1-16.

\section{CONCLUSION:}

[5] P.Duchowicz and E.A.Castro.,J.of the Korean Chemical Society 44 (6) (2000).

Therefore, standard heat enthalpies of for- [6] N.Cohen, J.Phys.Chem. Ref Data, 25 (6) (1995). mation $\left(\Delta \mathrm{H}_{\mathrm{f}}\right)^{\circ}$ ) of alkanes can be estimated by [7] B.L.Gorsi, G.S.Kalwania and M.Sharma, Indian equations(10),(11), (12) and (13) simply by calcu- $\quad$ J,Chem.,Sec.A, 32A(1993) 889.
[8] B.L.Gorsi,G.S.Kalwania and M.Sharma, J.Indian Chem lating molecular connectivity $\left({ }^{1} \chi^{\mathrm{v})}\right.$, van der waals Soc., 75 (1998) 373.

volume $\left(\mathrm{V}_{\mathrm{w}}\right)$, electrotopological state index (E) [9] L.B.Kier and L.H.,Hall ("Molecular Connectivity in and refractotopological state index (R) parame- Chemistry and Drug Research” Academic Press, New York ters. 1976.

[10] M. Randic, J. Am. Chem. Soc., 97 (1975) 6609.

[11] A. Bondi, J. Phy. Chem., 68 (1964) 441.

12] A. Moriguchi, Chem. Pharm. Bull. (Jpn.), 23 (1975) 247. [13] L. H. Hall , B. Mohnly and L. B. Kier , J. Chem. Inf. Compt. Sc., 1 (1991) 31.

\section{REFERENCES:}

[1] S. W. Benson and H. Buss , J. Chem. Phy., 29 (1958) 546 $-72$.

[14] L.H. Hall, B. Mohnly and L.B. Kier,Quant. Struct- Net., Relat, 10(1991) $43-51$.

[2] S. W. Benson , R. R .Cruickshank , D. M. Golden , G. [15] L. B. Kier and L. H., Hall , Pharmae Res., 7, 8 (1990) R. Haugen, H. E. O` Neal, A. S. Rodgers, R. J. Shaw and R. $801-807$.

Walsh, Chem. Rev., 69 (1969) 279 -321.

(1977) $90-100$.

[4] A.Mercader, E.A.Castro and A.A.Toropov,Int.J.Mol.Sci.2

[16] A. K. Ghose and G. M. Crippen , J.Chem. Inf. Comput. Sci. 27.1,(1987) $21-35$

[17] F. D. Rossini, K. S. Pitzer, R. L. Arnett, R. M. Braum and G. C. Pimentel, "Selected Values of Physical and Thermodynamic Properties of Hydrocarbons 